\title{
Successful Treatment of Cerebral Pheohyphomycosis Caused by Cladophialophora bantiana Infection in a Solid Organ Transplant Patient: A Case Report and a Review of Literature
}

\author{
Abraham Tareq Yacoub ${ }^{\mathrm{a}}$, Danielle Robinson ${ }^{\mathrm{b}}$, Kenneth Amaechi Onuorah ${ }^{\mathrm{c}}$, \\ Christine Fenlon ${ }^{\mathrm{d}}$, f John Greene ${ }^{\mathrm{e}}$
}

\begin{abstract}
We present a case of a 60 -year-old male with a past medical history of alpha-1-antitrypsin deficiency with lung transplantation in 2010, who was maintained on immunosuppressive agents, and was admitted to the hospital for neurological symptoms. Magnetic resonance imaging (MRI) of the brain revealed a ring-enhancing lesion. Microscopic evaluation of the abscess revealed fungus, and cultures grew Cladophialophora bantiana (C. bantiana). He was successfully treated with surgical abscess excision, liposomal amphotericin B and voriconazole.
\end{abstract}

Keywords: Cladophialophora bantiana; Solid organ transplant; Antifungals

\section{Introduction}

Cerebral pheohyphomycosis is a rare and frequently fatal fungal infection of the brain typically caused by Cladophialophora bantiana (C. bantiana), Exophiala dermatitidis, and Rhinocladiella mackenziei, all of which belong to the order Chaetothyr-

Manuscript submitted January 24, 2017, accepted February 10, 2017

${ }^{a}$ Department of Internal Medicine, Wilson Medical Center, United Health Services Hospitals, 33-57 Harrison St, Johnson City, NY, USA

${ }^{b}$ Lake Eerie College of Osteopathic Medicine, 1858 West Grandview Blvd., Eerie, PA 16509, USA

${ }^{\mathrm{c}}$ College of Osteopathic Medicine, New York Institute of Technology, Northern Boulevard, Old Westbury, NY, USA

${ }^{\mathrm{d}}$ Division of Infectious Diseases, Department of Internal Medicine, Wilson Medical Center, United Health Services Hospitals, 33-57 Harrison St, Johnson City, NY, USA

${ }^{\mathrm{e}} \mathrm{H}$. Lee Moffitt Cancer Center and Research Institute, University of South Florida College of Medicine, 12902 Magnolia Drive, Tampa, FL 33612-9497, USA

fCorresponding Author: Christine Fenlon, Department of Internal Medicine, Wilson Medical Center, United Health Services Hospitals, 33-57 Harrison St, Johnson City, NY, USA. Email: christine_fenlon@uhs.org

doi: https://doi.org/10.14740/jmc2763w iales [1]. These fungi are known as phaeoid or dematiaceous fungi, and are routinely characterized by intense melanin-like pigmentation of their cell walls, which is readily observed in hematoxylin and eosin stained sections [2]. Its mortality rate is high despite aggressive treatment [3]. C. bantiana accounts for the majority of cerebral pheohyphomycosis documented to date, and they are known to be highly neurotropic [3]. We report a case of cerebral pheohyphomycosis caused by $C$. bantiana successfully treated with surgical excision of the abscess, liposomal amphotericin B, and voriconazole.

\section{Case Report}

On September 30, 2014, a 60-year-old male with a past medical history of alpha-1-antitrypsin deficiency diagnosed in 1989 , who was status post lung transplantation in 2010, was admitted to the hospital for increased headache, photophobia, and gait disturbances. He had been in his baseline state of compromised health until about 7 days prior to this admission. He began noticing headaches that were located in the back of his neck, and were unremitting in nature. Then, 1 - 2 days prior to the admission, he started to have gait abnormalities. The patient denied having these symptoms before.

He had been on immunosuppressant agents including oral tacrolimus $1 \mathrm{mg}$ twice daily, oral azathioprine $200 \mathrm{mg}$ daily, and oral prednisone $5 \mathrm{mg}$ daily. In addition, he had been on antibiotic prophylaxis including oral azithromycin $250 \mathrm{mg}$ every Monday, Wednesday, and Friday, and oral trimethoprim/sulfamethoxazole (TMP/SMX) $800 \mathrm{mg} / 160 \mathrm{mg}$ every Monday, Wednesday, and Friday.

His vital signs included a temperature of $97.9^{\circ} \mathrm{F}(36.6$ ${ }^{\circ} \mathrm{C}$ ), heart rate of $74 / \mathrm{min}$, respiratory rate of $18 / \mathrm{min}$, blood pressure of 132/82 $\mathrm{mm} \mathrm{Hg}$, and an oxygen saturation of $96 \%$ on room air. The physical examination was unremarkable. He was alert, awake, and conversant with clear speech and mental status. His cranial nerves were well preserved with no nystagmus. Dysmetria and dysdiadochokinesia were present, and were more obvious on the right side of the body. He moved all four extremities reasonably with adequate muscle bulk and tone. There was no frank pronator drift or leg lag.

Laboratory findings included a white blood cell (WBC) 


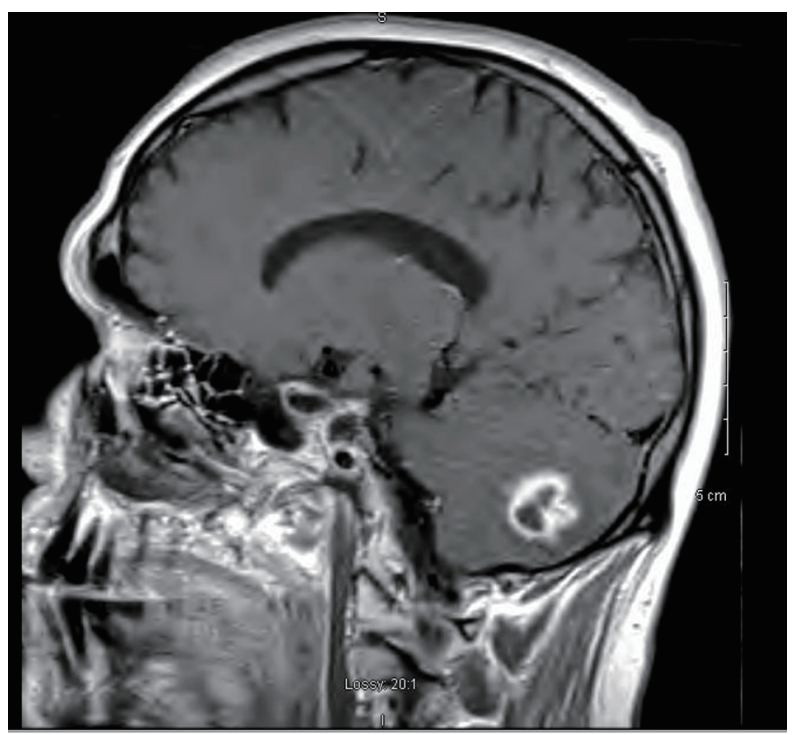

Figure 1. Magnetic resonance imaging (MRI), sagittal view. There is a $2.0 \mathrm{~cm}$ lobulated ring-enhancing right cerebellar mass with central restricted diffusion consistent with abscess. There is significant edema, mass effect and compression of the fourth ventricle.

count of $2.6 / \mathrm{mm}^{3}$, platelet count of $99,000 / \mu \mathrm{L}$, and hemoglobin of $11.7 \mathrm{~g} / \mathrm{dL}$. The chemistry panel revealed sodium of $137 \mathrm{mg} / \mathrm{dL}$, potassium of $4.3 \mathrm{mg} / \mathrm{dL}$, calcium of $9.2 \mathrm{mg} / \mathrm{dL}$, creatinine of $1.2 \mathrm{mg} / \mathrm{dL}$, blood urea nitrogen (BUN) of $26 \mathrm{mg} /$ $\mathrm{dL}$ and chloride of $101 \mathrm{mg} / \mathrm{dL}$.

A magnetic resonance imaging (MRI) of the brain (Fig. 1) revealed a $2.0 \mathrm{~cm}$ lobulated rim-enhancing right cerebellar mass with central restricted diffusion consistent with abscess.

Aspiration of the abscess revealed Staphylococcus sciuri. A peripherally inserted central catheter was placed and he was

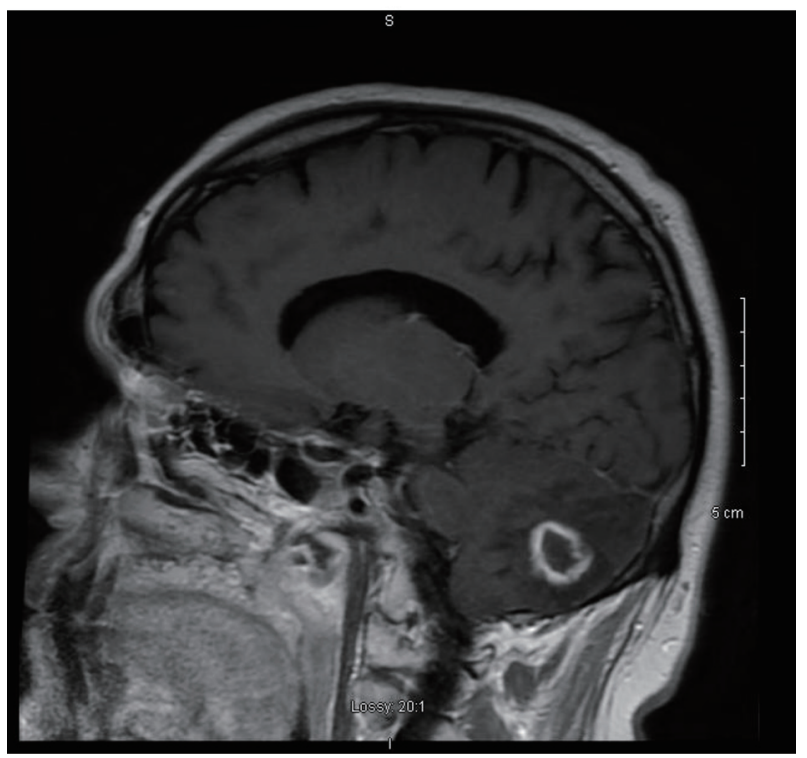

Figure 2. MRI, sagittal view. There is a $1.6 \times 1.8 \mathrm{~cm}$ ring-enhancing right cerebellar mass with extensive surrounding vasogenic edema and compression of the fourth ventricle.

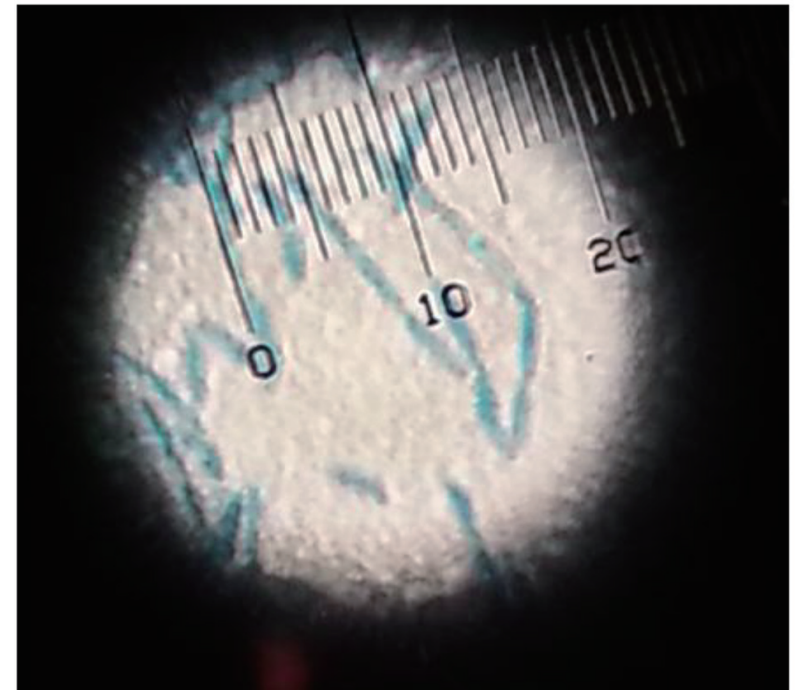

Figure 3. Lactophenol cotton blue preparation demonstrated pigmented septate hyphae.

discharged home on intravenous (IV) meropenem and vancomycin for a duration of 6 weeks.

On December 10, 2014, the patient was admitted once more for worsening headaches and photophobia. The headaches started 5 days before his admission, and were located behind his right eye. He was very unstable on his feet, and the left side of his body displayed weakness. He denied any nausea, vomiting, blurred vision, fever, chills or sweats. His vital signs were within normal limits and the physical examination was unremarkable.

Laboratory findings included a WBC count of $7.5 / \mathrm{mm}^{3}$, platelet count of $95,000 / \mu \mathrm{L}$, and hemoglobin of $11.2 \mathrm{~g} / \mathrm{dL}$.

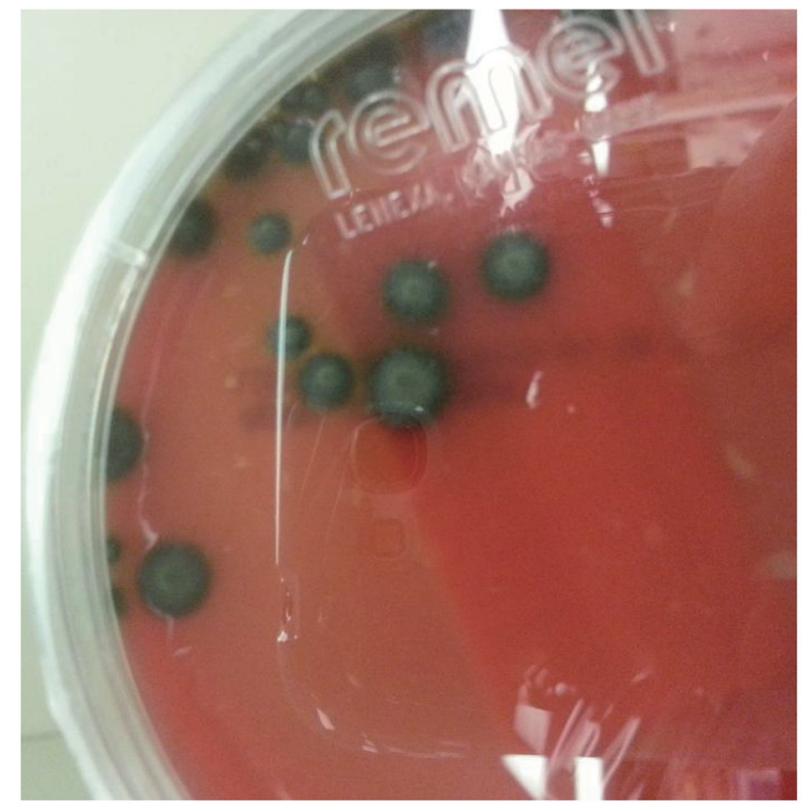

Figure 4. Sheep red blood agar plate grew mucoid dark pigmented colonies. 


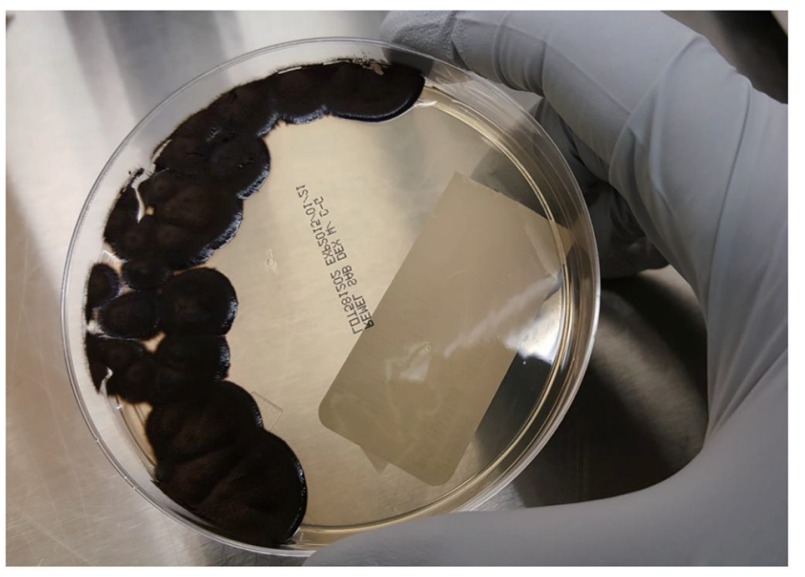

Figure 5. Sabouraud agar plate grew mucoid dark pigmented colonies.

Electrolytes demonstrated sodium of $135 \mathrm{mg} / \mathrm{dL}$, potassium of $4.1 \mathrm{mg} / \mathrm{dL}$, chlorine of $103 \mathrm{mg} / \mathrm{dL}, \mathrm{BUN}$ of $20 \mathrm{mg} / \mathrm{dL}$ and creatinine of $1.1 \mathrm{mg} / \mathrm{dL}$.

A repeat MRI of the brain (Fig. 2) revealed a right $1.6 \times$ $1.8 \mathrm{~cm}$ rim-enhancing right cerebellar mass with extensive surrounding vasogenic edema. The patient underwent a stealth directed resection of the right cerebellar brain abscess. Samples from this procedure ultimately grew fungus (Figs. 3-5). The patient was empirically treated with course of IV liposomal amphotericin B for a duration of 6 weeks and voriconazole for a duration of 12 weeks. The patient was treated successfully and his neurologic deficits improved.

\section{Discussion}

Cerebral pheohyphomycosis is a rare infection caused by the fungus $C$. bantiana. $C$. bantiana is a member of the order Chaetothyriales, which is often referred to as "black yeast-like fungi" due to the ability of some representatives to produce budding cells as well as dark hyphae, depending on the life cycle and environmental conditions [4]. It is the most common cause of central nervous system (CNS) infections caused by the dematiaceous pigmented fungi [5]. The pigmented nature of this organism has been shown to be due to melanin production, and this feature may assist the organism with evading host defenses $[6,7]$.

Although the portal of entry for infection is frequently obscure, many fungi are thought to be blood-borne from the lungs or intestines $[7,8]$. Primary infection in the middle ear and paranasal sinuses can subsequently spread to the CNS [8]. It can present in the form of cerebritis, meningitis, or abscess (most common clinical manifestation) [5, 9-11].

The risk factors for $C$. bantiana infection include those which suppress cell-mediated immunity, such as organ transplantation, cancer, and immunosuppressive agents [12]. In one study by Chakrabarti et al, researchers revealed that the majority of these cases were found in males who came from Asian countries [13]. Interestingly, $C$. bantiana infection was nearly equally distributed in the immunocompetent and the immunosuppressed hosts [13]. The most common symptom was headaches, followed by hemiparesis, seizures, and altered sensorium $[13,14]$.

Histopathological and microbiological examinations are the diagnostic tool of choice since fungal brain abscess cannot be differentiated from bacterial cerebral abscess, primary CNS tumor, and cerebral metastasis by imaging studies, according to Huang et al [15]. However, a study done by Hauck et al mentioned that magnetic resonance diffusion-weighted imaging apparent diffusion coefficient MRI may add valuable information for the imaging differential diagnosis of fungal abscess versus bacterial abscess versus high-grade glioma [16]. There has also been use of genetic analysis to help in the diagnosis of C. bantiana in China [15].

Current treatment recommendations in solid organ transplant (SOT) patients from the American Society of Transplantation Infectious Diseases Community of Practice regarding pheohyphomycosis identify itraconazole, voriconazole, and posaconazole as first-line therapy [17-19]. Amphotericin B is not recommended as a first-line therapy in the setting of cerebral abscess due to concern for excess failure rates [19]. However, our study noted voriconazole and amphotericin B were the most commonly used antifungal agents. Voriconazole has been used in a number of case reports due to its broad activity against dematiaceous fungi and its good cerebrospinal fluid penetration. The use of itraconazole has excellent brain tissue penetration and can be used if voriconazole cannot be tolerated [20]. Flucytosine is effective; however, its use is limited due to bone marrow suppression, especially in immunocompromised patients [21]. Fluconazole and echinocandins are not effective against C. bantiana [21].

The Staphylococcus sciuri was ultimately believed to be a skin contaminant. This delayed appropriate antifungal therapy and underscores the need for surgical resection of the abscess for diagnosis and treatment.

We reviewed the literature (Table 1 [21-29]) of patients who underwent SOT that were subsequently on immunosuppressant therapy and developed this rare CNS infection. The average age was 39 years and the median age was 38 years. There were six males and four females. Five patients had kidney transplant, two patients had liver transplant, three patients had heart transplant, and two patients had lung transplant. The most common types of immunosuppressive agents used were corticosteroids, azathioprine, and cyclosporine. The most common presentation was headache. Thirty percent of the patients had an abscess located in the parietal region and cerebellum, $20 \%$ in the temporoparietal region, and $10 \%$ in the frontal region. The most common antifungal agent used was amphotericin B. Six patients expired and three patients were cured.

\section{Conclusion}

Cerebral pheohyphomycosis is a deadly infection with high morbidity and mortality, despite aggressive treatment. Complete excision of brain lesions may provide better results than simple aspiration. An aggressive medical and surgical approach is warranted in treating these infections to optimize outcomes. Although rare, it is important for clinicians to keep this fungal infection in their differential diagnosis. 

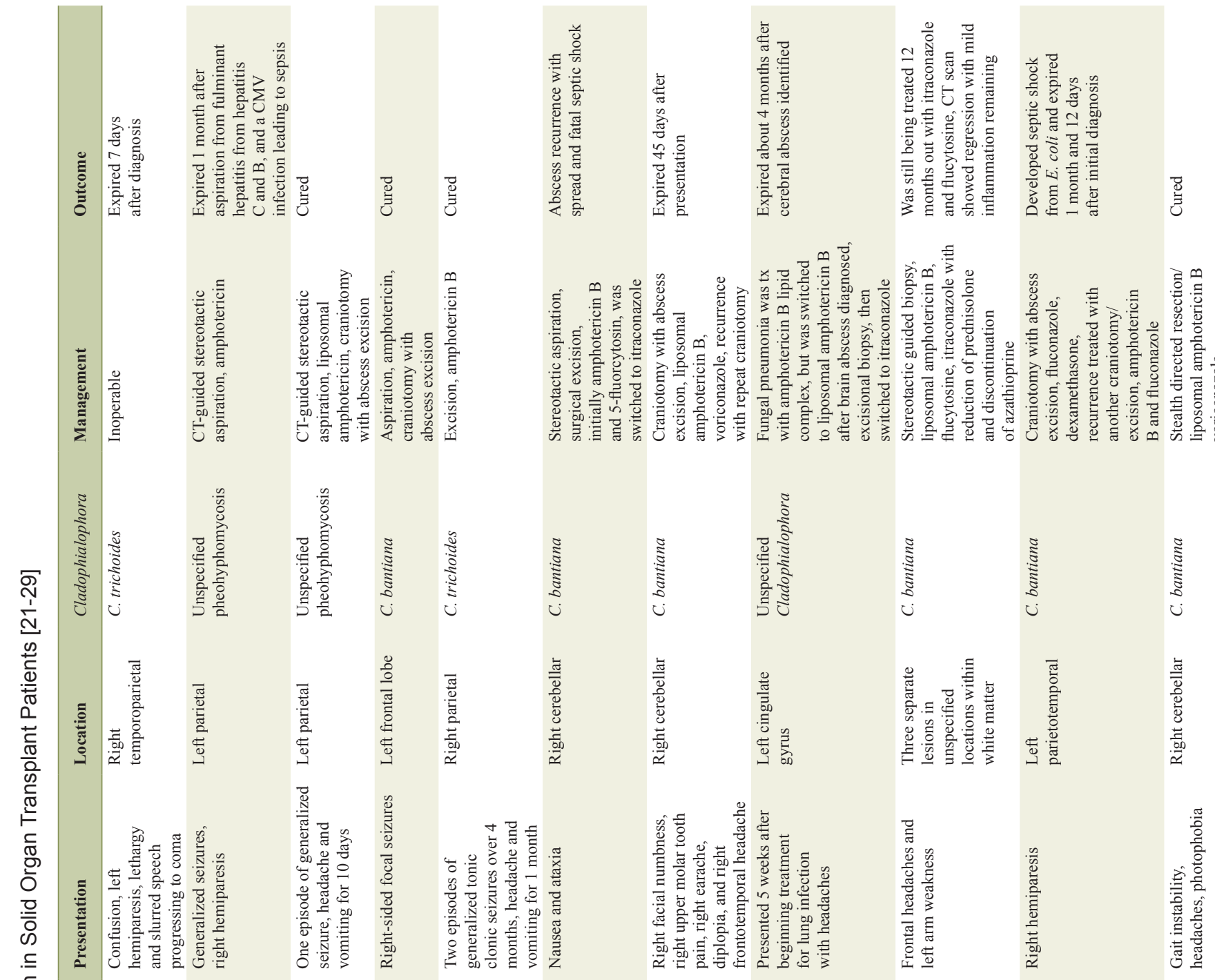

亏ั)

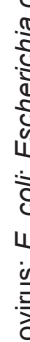

임

음

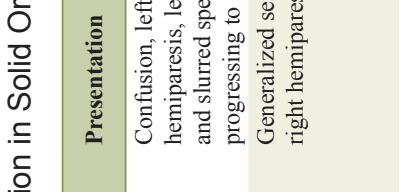

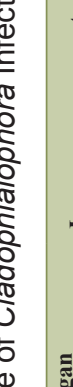

(2)
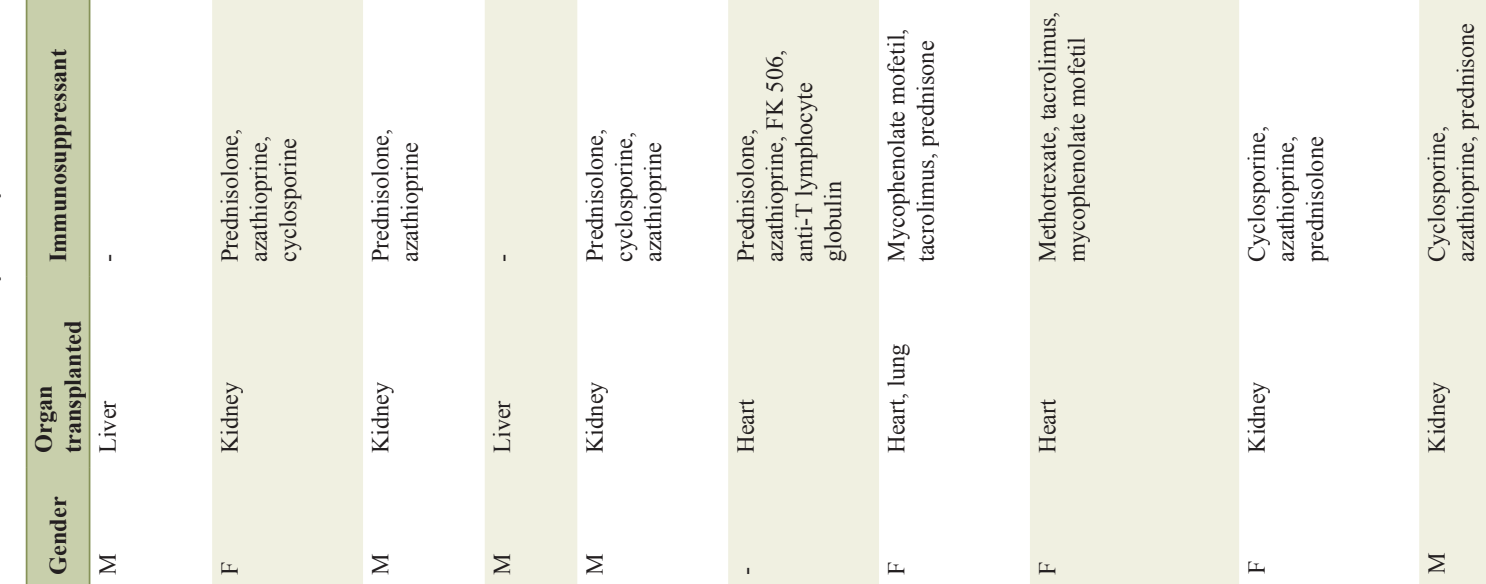


\section{Conflict of Interest}

The authors have no conflict of interest to disclose.

\section{Funding}

None.

\section{References}

1. Li DM, de Hoog GS. Cerebral phaeohyphomycosis - a cure at what lengths? Lancet Infect Dis. 2009;9(6):376-383.

2. Rawal YB, Kalmar JR. Intraoral phaeohyphomycosis. Head Neck Pathol. 2012;6(4):481-485.

3. Nandedkar S, Bajpai T, Bhatambare GS, Sakhi P. Cerebral phaeohyphomycosis: A rare case from central India. Asian J Neurosurg. 2015;10(2):142-144.

4. Rantala M, Attia S, Koukila-Kahkola P, de Hoog S, Anttila M, Katila T. Cladophialophora bantiana as an Emerging Pathogen in Animals: Case Report of Equine Endometritis and Review of the Literature. J Clin Microbiol. 2015;53(9):3047-3053.

5. Mansour A, Jordan K. Disseminated Cladophialophora bantiana disease in a patient with prediabetes. BMJ Case Rep. 2014;2014.

6. Mason SE, Dueker ND, Stratton CW, Whetsell WO, Jr. An 80-year-old man with a ring-enhancing right basal ganglia lesion. Brain Pathol. 2008;18(2):288-291.

7. Martinez-Lamas L, Alvarez M, Llovo J, Gene J, Cano J. Phaeohyphomycosis caused by Cladophialophora bantiana. Rev Iberoam Micol. 2014;31(3):203-206.

8. Brown JW, 3rd, Nadell J, Sanders CV, Sardenga L. Brain abscess caused by Cladosporium trichoides (Bantianum): a case with paranasal sinus involvement. South Med J. 1976;69(11):1519-1521.

9. Mukherji SK, Castillo M. Cerebral phaeohyphomycosis caused by Xylohypha bantiana: MR findings. AJR Am J Roentgenol. 1995;164(5):1304-1305.

10. Buxi TB, Prakash K, Vohra R, Bhatia D. Imaging in phaeohyphomycosis of the brain: case report. Neuroradiology. 1996;38(2):139-141.

11. Moja M, Muthuphei MN, van der Westhuizen LR, Gledhill RF. Multiple infarcts in a patient with cerebral phaeohyphomycosis: CT and MRI. Neuroradiology. 2000;42(4):261-266.

12. Alhabib KF, Bryce EA. Xylohypha bantiana multiple brain abscesses in a patient with systemic lupus erythematosus. Can J Infect Dis. 2003;14(2):119-120.

13. Chakrabarti A, Kaur H, Rudramurthy SM, Appannanavar SB, Patel A, Mukherjee KK, Ghosh A, et al. Brain abscess due to Cladophialophora bantiana: a review of 124 cases. Med Mycol. 2016;54(2):111-119.

14. Pham LV, Quang AT, Ton Nu PA, Duc TT, Thi HN. Cladophialophora bantiana and Candida albicans mixed infection in cerebral abscess of an HIV-negative patient. J
Infect Dev Ctries. 2008;2(3):245-248.

15. Huang WM, Fan YM, Li W, Yang WW. Brain abscess caused by Cladophialophora bantiana in China. J Med Microbiol. 2011;60(Pt 12):1872-1874.

16. Hauck EF, McGinnis M, Nauta HJ. Cerebral phaeohyphomycosis mimics high-grade astrocytoma. J Clin Neurosci. 2008;15(9):1061-1066.

17. Ben-Ami R, Lewis RE, Raad II, Kontoyiannis DP. Phaeohyphomycosis in a tertiary care cancer center. Clin Infect Dis. 2009;48(8):1033-1041.

18. Trinh JV, Steinbach WJ, Schell WA, Kurtzberg J, Giles SS, Perfect JR. Cerebral phaeohyphomycosis in an immunodeficient child treated medically with combination antifungal therapy. Med Mycol. 2003;41(4):339-345.

19. McCarty TP, Baddley JW, Walsh TJ, Alexander BD, Kontoyiannis DP, Perl TM, Walker R, et al. Phaeohyphomycosis in transplant recipients: Results from the Transplant Associated Infection Surveillance Network (TRANSNET). Med Mycol. 2015;53(5):440-446.

20. Revankar SG. Cladophialophora bantiana brain abscess in an immunocompetent patient. Can J Infect Dis Med Microbiol. 2011;22(4):149-150.

21. Garzoni C, Markham L, Bijlenga P, Garbino J. Cladophialophora bantiana: a rare cause of fungal brain abscess. Clinical aspects and new therapeutic options. Med Mycol. 2008;46(5):481-486.

22. Aldape KD, Fox HS, Roberts JP, Ascher NL, Lake JR, Rowley HA. Cladosporium trichoides cerebral phaeohyphomycosis in a liver transplant recipient. Report of a case. Am J Clin Pathol. 1991;95(4):499-502.

23. Arunkumar MJ, Rajshekhar V, Chandy MJ, Thomas PP, Jacob CK. Management and outcome of brain abscess in renal transplant recipients. Postgrad Med J. 2000;76(894):207-211.

24. Choudhury S, Aggarwal R, Supraja C, Rao S, D'Cruz A. 29 cladophialophora bantiana causing brain abscess following liver transplant-a case report. J Clin Exp Hepatol. 2011;1(2):146.

25. Gupta SK, Manjunath-Prasad KS, Sharma BS, Khosla VK, Kak VK, Minz M, Sakhuja VK. Brain abscess in renal transplant recipients: report of three cases. Surg Neurol. 1997;48(3):284-287.

26. Keyser A, Schmid FX, Linde HJ, Merk J, Birnbaum DE. Disseminated Cladophialophora bantiana infection in a heart transplant recipient. J Heart Lung Transplant. 2002;21(4):503-505.

27. Levin TP, Baty DE, Fekete T, Truant AL, Suh B. Cladophialophora bantiana brain abscess in a solid-organ transplant recipient: case report and review of the literature. J Clin Microbiol. 2004;42(9):4374-4378.

28. Osiyemi OO, Dowdy LM, Mallon SM, Cleary T. Cerebral phaeohyphomycosis due to a novel species: report of a case and review of the literature. Transplantation. 2001;71(9):1343-1346.

29. Salama AD, Rogers T, Lord GM, Lechler RI, Mason PD. Multiple Cladosporium brain abscesses in a renal transplant patient: aggressive management improves outcome. Transplantation. 1997;63(1):160-162. 